\title{
Cyba-deficient mice display an increase in hematopoietic stem cells and an overproduction of immunoglobulins
}

\author{
Rodrigo Prieto-Bermejo, ${ }^{1,2}$ Marta Romo-González, ${ }^{1,2 *}$ Alejandro Pérez- \\ Fernández, ${ }^{1,2^{\star}}$ Ignacio García-Tuñón, ${ }^{3}$ Manuel Sánchez-Martín ${ }^{2,4,5}$ \\ and Ángel Hernández-Hernández ${ }^{1,2}$
}

Haematologica 2021

Volume 106(1):142-153

${ }^{1}$ Departamento de Bioquímica y Biología Molecular, Universidad de Salamanca; ${ }^{2}$ Instituto de Investigación Biomédica de Salamanca (IBSAL); ${ }^{3}$ Unidad de Diagnóstico Molecular y Celular del Cáncer, Centro de Investigación del Cáncer-IBMCC (USAL-CSIC); ${ }^{4}$ Servicio de Transgénesis, Nucleus, Universidad de Salamanca and ${ }^{5}$ Departamento de Medicina, Universidad de Salamanca, Salamanca, Spain

*MR-G and AP-F contributed equally to this work.

\section{ABSTRACT}

The regulation of protein function by reversible oxidation is increasingly recognized as a key mechanism for the control of cellular signaling, modulating crucial biological processes such as cell differentiation. In this scenario, NADPH oxidases must occupy a prominent position. Our results show that hematopoietic stem and progenitor cells express three p22 $2^{\text {phox }}$-dependent NADPH oxidase members (NOX1, NOX2 and NOX4). By deleting the $\mathrm{p} 22^{\text {phox }}$ coding gene $(C y b a)$, here we have analyzed the importance of this family of enzymes during in vivo hematopoiesis. Cyba- mice show a myeloid bias, and an enrichment of hematopoietic stem cell populations. By means of hematopoietic transplant experiments we have also tried to dissect the specific role of the NADPH oxidases. While the absence of NOX1 or NOX2 provides a higher level of reconstitution, a lack of NOX4 rendered the opposite result, suggesting a functional specificity among the different NADPH oxidases. Cyba cells showed a hampered activation of AKT1 and a sharp decrease in STAT5 protein. This is in line with the diminished response to IL-7 shown by our results, which could explain the overproduction of immunoglobulins observed in $C y b a^{-/}$mice.

\section{Correspondence:}

ÁNGEL HERNÁNDEZ-HERNÁNDEZ angelhh@usal.es

Received: July 19, 2019.

Accepted: January 2, 2020.

Pre-published: January 9, 2020.

https://doi.org/10.3324/haematol.2019.233064

(C)2021 Ferrata Storti Foundation

Material published in Haematologica is covered by copyright. All rights are reserved to the Ferrata Storti Foundation. Use of published material is allowed under the following terms and conditions:

https://creativecommons.org/licenses/by-nc/4.0/legalcode. Copies of published material are allowed for personal or internal use. Sharing published material for non-commercial purposes is subject to the following conditions:

https://creativecommons.org/licenses/by-nc/4.0/legalcode, sect. 3. Reproducing and sharing published material for commercial purposes is not allowed without permission in writing from the publisher.

\section{Introduction}

From being considered harmful metabolic by-products, reactive oxygen species (ROS) have turned out to be important regulators of cellular biology, by acting as bona fide secondary messengers. ${ }^{1-3}$ NADPH oxidases are the only cellular system specialized in the production of ROS. ${ }^{4}$ The founding member of this family is phagocyte oxidase, a multiprotein complex that produces huge amounts of superoxide during respiratory burst, which is required for the elimination of pathogens. ${ }^{4}$ The complex consists of two integral membrane proteins ( $\mathrm{p} 22^{\text {phox }}$, and the catalytic subunit, named gp91 ${ }^{\text {phox }}$ or NOX2), three cytosolic subunits ( $\mathrm{p} 40^{\text {phox }}, \mathrm{p} 47^{\text {phox }}, \mathrm{p} 67^{\text {phox }}$ ), and the Rac GTPase. ${ }^{4,5}$ Inactivating mutations affecting the complex produce chronic granulomatous disease (CGD), a hematological disorder characterized by the occurrence of repetitive infections. ${ }^{6}$

For quite some time the NADPH oxidase from phagocytes seemed to be the only oxidase. However, in 1999 cloning and characterization of NOX1 was reported, which was followed by the discovery of other homologues oxidases. Nowadays the family comprises seven members, which can be classified into two groups, those dependent on $\mathrm{p} 22^{\text {phox }}$ (NOX1, NOX2, NOX3, NOX4), and those p22 $2^{\text {phox }}$-independent that can be activated by calcium (NOX5, DUOX1 and DUOX2), ${ }^{4,5}$ These enzymes are present in all eukaryotic cells, including unicellular organisms, ${ }^{8}$ and several members of the family are commonly expressed simultaneously. ${ }^{4}$ This broad distribution and its regulation by extracellular signaling make NADPH oxidases a key element in redox signaling.

ROS and NADPH oxidases are involved in the control of cell fate..$^{2,9-11}$ 
Hematopoiesis is a paradigmatic example of cell differentiation, because hematopoietic stem cells (HSC) must produce all mature blood lineages. There is increasing evidence suggesting the importance of redox signaling for hematopoietic differentiation, as well as for the contribution of an elevated level of ROS in the development of leukemia., ${ }^{2,3}$ Our previous data has shown the requirement of NADPH oxidase-produced ROS for in vitro megakaryocytic differentiation. ${ }^{12}$ However, even though NADPH oxidases were discovered in the hematopoietic system, knowledge of the importance of these enzymes for hematopoiesis in vivo is scarce. This analysis has surely been hampered by the fact that hematopoietic cells express several NADPH oxidase isoforms (our unpublished data and ${ }^{13}$ ).

Here we have analyzed the relevance of NADPH oxidases during in vivo hematopoiesis. Mouse hematopoietic progenitor cells express NOX1, NOX2 and NOX4, all of them $\mathrm{p} 22^{\text {phox }}$-dependent. In order to assess the importance of NADPH oxidase activity for in vivo hematopoiesis we have generated p $22^{\text {phox }}$-deficient mice $\left(\mathrm{Cy} b \mathrm{a}^{-/}\right)$. The lack of p22 phox induces a myeloid bias. Moreover, there is an increased proportion of HSC in the bone marrow (BM). In competitive transplant experiments, cells deficient in

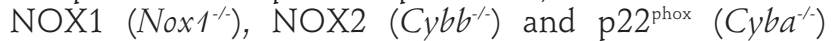
showed an increased reconstitution ability with respect to control cells. However, NOX4 (Nox $\left.4^{-1}\right)$ deficient cells did not show this effect. The response of Cyba cells to IL-7 is severely impaired, which can be explained by a hampered activation of AKT1 and by the reduction in STAT5 protein levels. These redox signaling alterations could be the cause of the increased production of immunoglobulins observed in Cyba mice.

\section{Methods}

\section{Animals}

C57BL/6 mice were from the University of Salamanca Animal Facility Unit. Albino C57BL/6 mice (B6(Cg)-Tyr ${ }^{(-2 J J)}$, Nox1

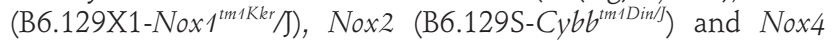
(B6.129-Nox4 $\left.4^{t m / K k r} / \mathrm{J}\right)$ deficient mice were from Jackson Laboratory (Bar Harbor, ME, USA). Cyba $a^{-/-}$models were generated as detailed in the Online Suplementary Materials and Methods. All procedures were approved by the Bioethics Committee at the University of Salamanca.

\section{ROS detection}

Peripheral blood (PB) was lysed to eliminate red blood cells. ROS levels were detected by cell staining with $10 \mu \mathrm{M}$ DCFDA $(2,7 \text {-dichlorodihydrofluorescein diacetate })^{12}$ or with $100 \mu \mathrm{M}$ luminol ${ }^{14}$ after stimulation with $2 \mu \mathrm{M}$ PMA (phorbol-12-myristate-13-acetate).

\section{Colony forming unit (CFU) assays}

Cells were grown in methylcellulose semisolid medium supplemented with a cocktail of cytokines (50 ng/mL SCF, $20 \mathrm{ng} / \mathrm{mL}$ IL$3,20 \mathrm{ng} / \mathrm{mL}$ GM-CSF and $3 \mathrm{U} / \mathrm{mL}$ EPO), or with individual cytokines (IL-3, GM-CSF, and IL-7) at $20 \mathrm{ng} / \mathrm{mL}$. 200,000 spleen and 10,000 BM cells (200,000 with IL-7) were used. Cells were grown at $37^{\circ} \mathrm{C}$ and $5 \% \mathrm{CO}_{2}$ for 12 days.

\section{BM transplantation}

C57BL/6 recipient mice were lethally irradiated with two doses of 5 Gy from a Cs source (Gammacell 1,000 Elite, Nucleus Facility,
University of Salamanca) as previously described..$^{15}$ Recipient mice were injected intravenously through the lateral tail vein with $3 \times 10^{6} \mathrm{BM}$ cells from ES Cyba/ or from wild-type C57BL/6 mice. Competitive transplant experiments were performed by injecting $1.5 \times 10^{6} \mathrm{BM}$ cells from NADPH oxidase deficient mice (Nox ${ }^{-\%}$, $\mathrm{Cy}_{\mathrm{bb}} \mathrm{b}^{-1}$, Nox $4^{-1}$ or ES $\mathrm{Cyba} \mathrm{a}^{-/}$) or from C57BL/6 control mice, together with $1.5 \times 10^{6} \mathrm{BM}$ competitor cells from wild-type C57BL/ 6 mice. Cell origin was assessed by the differential expression of the CD45.1 and CD45.2 isotypes. Secondary transplants were carried out 18 weeks post-first transplant, by injecting $3 \times 10^{6}$ $\mathrm{BM}$ cells from the primary transplanted mice into lethally irradiated C57BL/6 mice.

\section{In vivo bromodeoxyuridine incorporation assay}

Mice were intraperitoneally treated with $100 \mathrm{mg} / \mathrm{kg}$ 5-bromo 2' -deoxyuridine (BrdU) and sacrificed 14 hours postinjection. The percentage of $\mathrm{BrdU}^{+}$proliferating cells was analyzed by flow cytometry as previously described. ${ }^{15}$

\section{RNA sequencing analysis}

cDNA libraries were compiled using the Illumina TruSeq RNA Library Preparation Kit v2, with $2 \mu \mathrm{g}$ of total RNA from immunopurified Lin ${ }^{-}$cells. ${ }^{15}$ Single-end 150 nt length sequencing was performed on an Illumina NextSeq 500 System using a Mid Output kit v2.5 from Illumina. Reads obtained were compared against the GRCm38 mouse genome using the bioinformatic facility tool of the University of Salamanca (https://ranaseq.eu/home). GEO accession: GSE131725

\section{Immunoblotting}

Immunoblotting and quantification of bands were performed as previously described, ${ }^{16}$ and using fluorescently labelled secondary antibodies with an Odyssey Infrared Imaging System (Li-Cor). VINCULIN was used as a loading control.

\section{Statistical analyses and data report}

Data are expressed as mean values \pm standard deviation. In dot graphs, each dot represents an individual value and the horizontal line denotes the mean value. Data were analyzed with SPSS 23 software. Two-tailed unpaired Student's $t$ test was used, and differences were considered statistically significant when $P<0.05\left(^{*}\right)$,

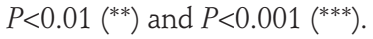

\section{Results}

\section{p22 ${ }^{\text {phox }}$ knockout mice (Cyba ${ }^{\circ}$ ) are viable and} present a bias towards the myeloid lineage

In agreement with our former analysis on human hematopoietic cells, ${ }^{13}$ mice progenitor Lin $^{-}$cells express several NOX isoforms (NOX1, NOX2 and NOX4) (Figure $1 \mathrm{~A}$ and Online Supplementary Figure S1). Since all of them are $\mathrm{p} 22^{\text {phox }}$-dependent, ${ }^{4,5}$ we reasoned that a $\mathrm{p} 22^{\text {phox }}$-deficient mouse model would allow the analysis of the relevance of NADPH oxidase activity for in vivo hematopoiesis. p22 $2^{\text {phox }}$ knockout mice were generated using either embryonic stem (ES) cells, or CRISPR/Cas9 technology. These mice will be named hereafter as ES Cyba and CR Cyba respectively. Mice were genotyped by PCR and Southern blotting (Online Supplementary Figure S2). The absence of the $\mathrm{p} 22^{\text {phox }}$ protein was confirmed by Western blotting (Figure 1B). Cyba mice were viable and displayed equilibrium defects denoted by a clear inclination of the head. This head-tilt phenotype has been reported before for a $22^{\text {phox }}$ hypomorphic mutant, ${ }^{17}$ and it 
A
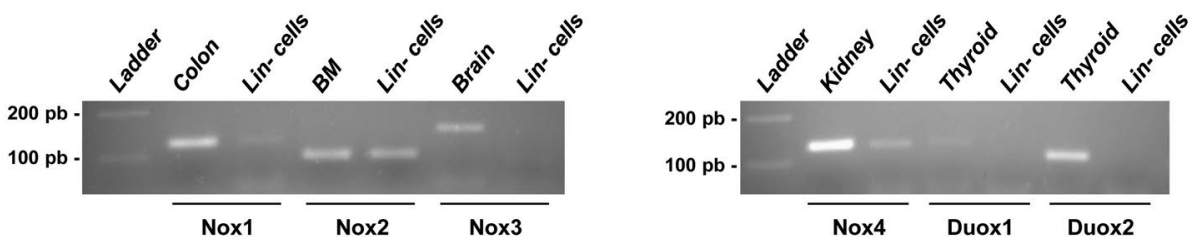

B
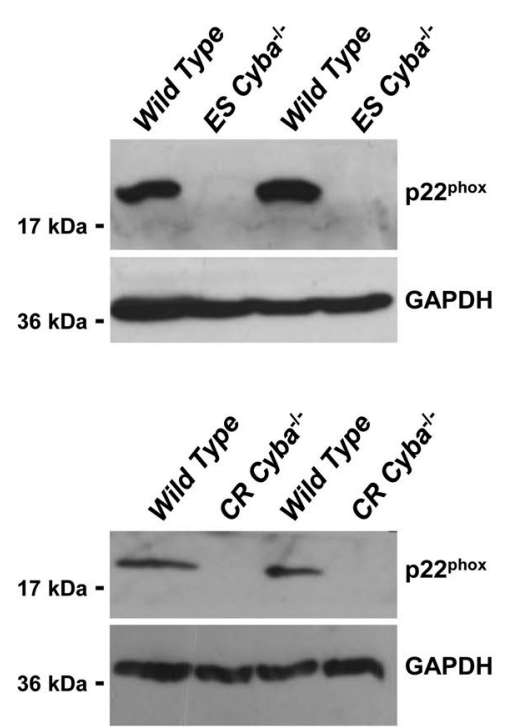

E

○ Wild Type • ES Cyba -/-

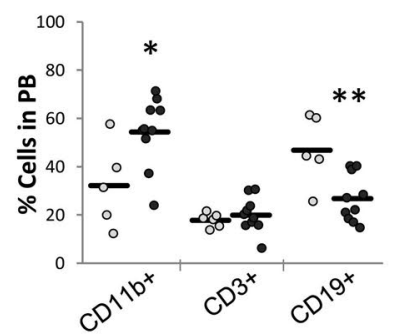

$\mathrm{F}$

- Wild Type - CR Cyba -/-

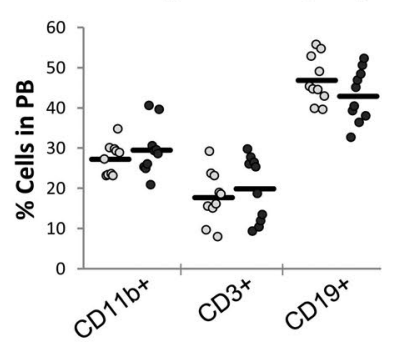

\section{C}

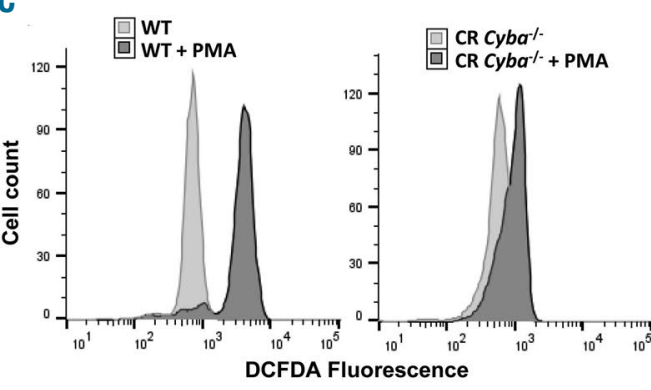

口Wild Type $\square$ CR Cyba - /-

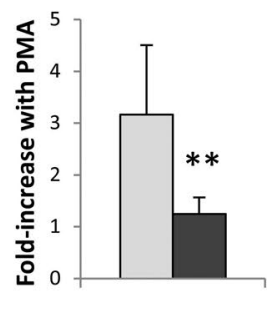

D

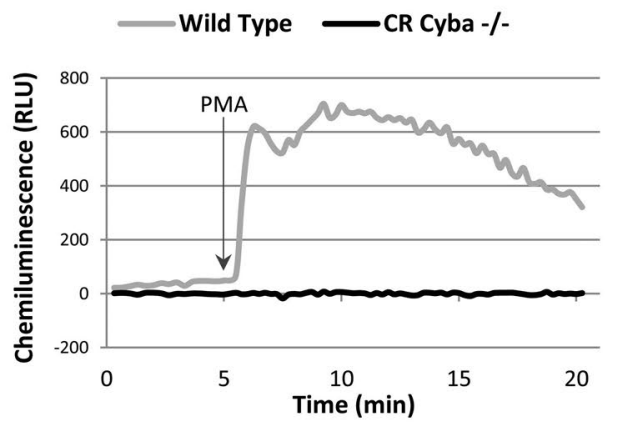

口Wild Type $\square$ CR Cyba -/-

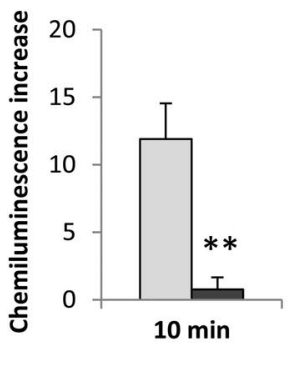

Figure 1. The lack of Cyba gene induces a myeloid bias. (A) NADPH oxidase expression in Lin progenitor cells analyzed by RT-PCR. The tissues indicated in the figure were used as positive controls $(n=2)$. (B) Representative blots of p22 $2^{\text {phox }}$ protein expression in wild-type, ES Cyba and CR Cyba mice $(n=4)$. (C) Peripheral blood cells were stimulated with $2 \mu \mathrm{M}$ phorbol 12-myristate 13-acetate (PMA) for $30 \mathrm{~min}$. The level of reactive oxygen species (ROS) was analyzed in the granulocyte population. A representative flow cytometry experiment and the mean \pm standard deviation (SD) of the ROS fold-increase of seven different experiments are shown. (D) 200,000 peripheral blood (PB) cells were incubated with $100 \mu \mathrm{M}$ luminol, and chemiluminescence was monitored for 15 min at $37^{\circ} \mathrm{C}$ after addition of $2 \mu \mathrm{M}$ PMA. A representative experiment showing the RLU (relative luminescence units) and the mean \pm SD of the chemiluminescence fold-increase at 10 min of three different experiments are shown. (E) Analysis of hematopoietic lineages in ES Cyba and control mice. (F) Analysis of hematopoietic lineages in CR Cyba and control mice. 
A
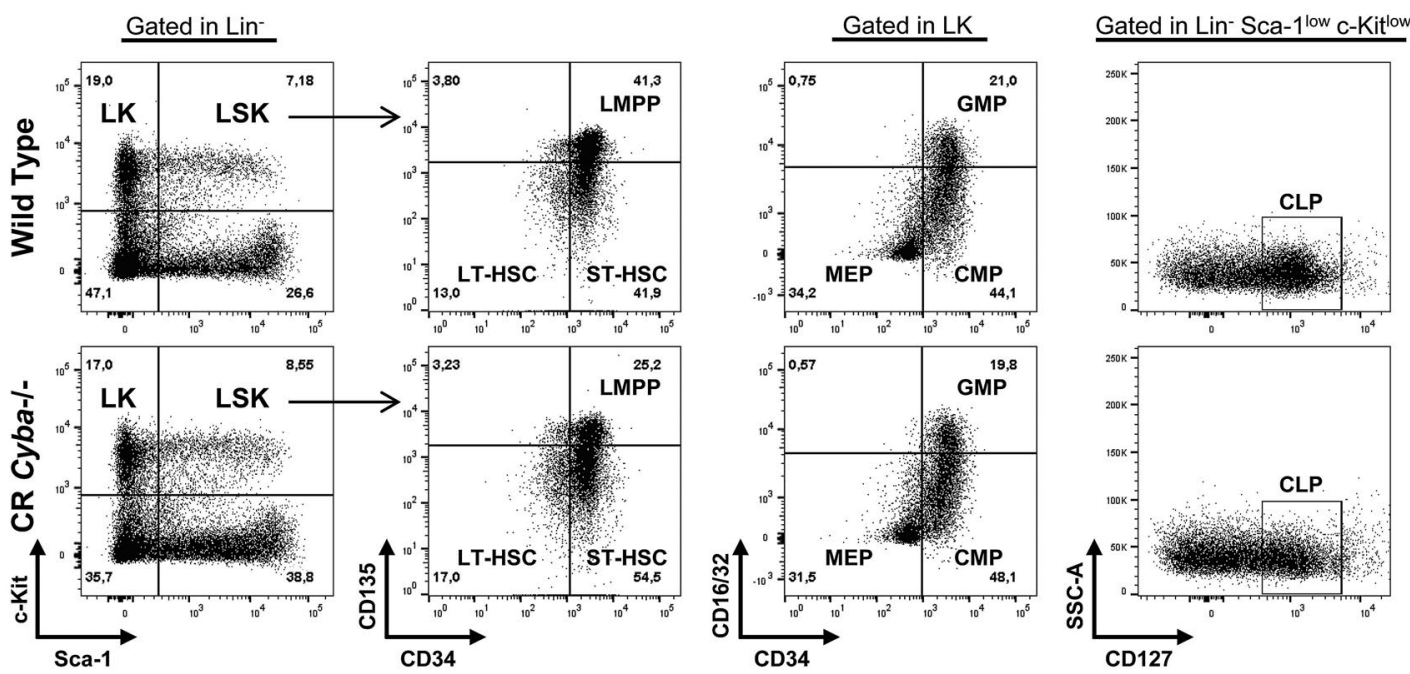

B

○ Wild Type • CR Cyba - $/-$
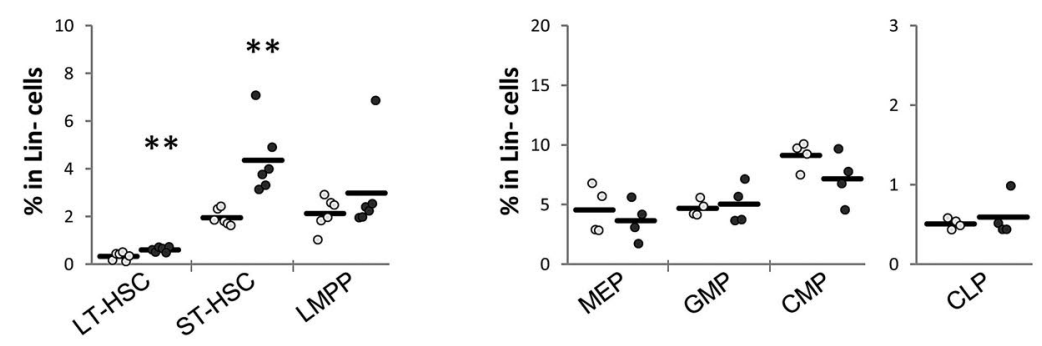

C

○ Wild Type • ES Cyba -/-
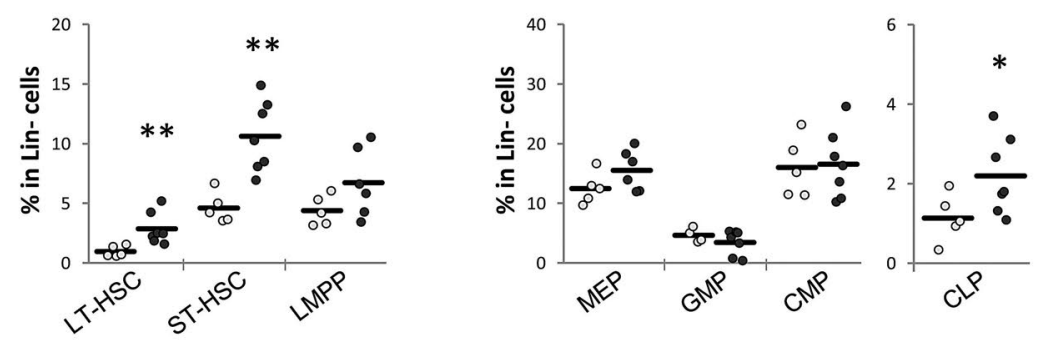

D

O Wild Type - ES Cyba -/-
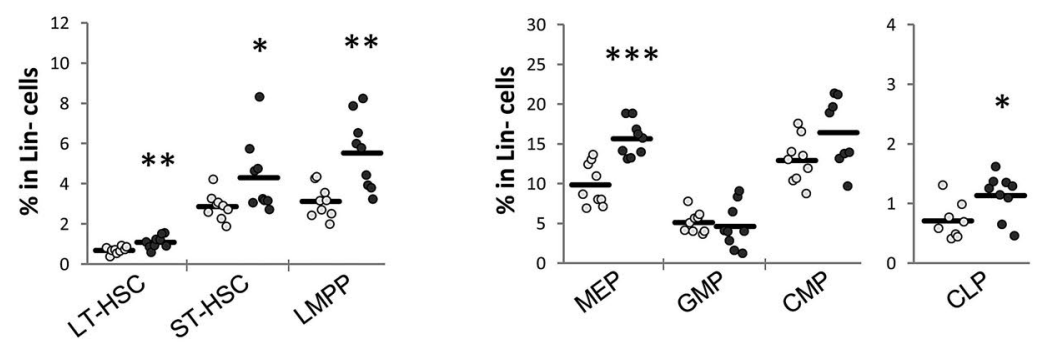

Figure 2. Bone marrow cells from Cyba mice are enriched in hematopoietic stem cells. (A) Representative flow cytometry analysis of the hematopoietic stem cells (HSC) populations in CR Cyba and control mice. (B) Percentages of the different stem and progenitor populations in CR Cyba and control mice. (C) Percentages of the different stem and progenitor populations in ES Cyba and control mice. (D) Analysis of stem and progenitor cell populations at 20 weeks post-transplantation in lethally irradiated mice transplanted with wild-type or ES Cyba cells. LK: lineage-committed progenitors; LSK: Lin Sca-1 ${ }^{+}$c-Kit ${ }^{+}$hematopoietic stem cells; LMPP: lymphoid-primed multipotent progenitors; LT-HSC: Iong-term HSC; ST-HSC: short-term HSC; GMP: granulocyte-monocyte progenitors; MEP: megakaryocyte-erythrocyte progenitors; CMP: common myeloid progenitors, CLP: common lymphoid progenitors. 
is suggested to be due to the requirement of NOX3 activity for otoconia synthesis. ${ }^{18}$

The lack of NADPH oxidase activity in Cyba mice was checked by measuring the levels of extracellular and intracellular ROS after stimulating NADPH oxidase with PMA (Figure 1C-D and Online Supplementary Figure S3).

ES Cyba mice showed a significant increase in CD $11 b^{+}$ myeloid cells in $\mathrm{PB}$ and spleen. A general increase of $\mathrm{CD}_{11 \mathrm{~b}^{+}}$myeloid cells is also observed in the BM, though not statistically significant (Figure 1E). These results support the existence of a myeloid bias in ES Cyba mice, a notion that is further supported by analysis of CR Cyba mice, which shows a significant increase in myeloid cells in $\mathrm{BM}\left(\mathrm{CD} 11 \mathrm{~b}^{+} \mathrm{Gr}^{-}\right.$cells) and in spleen $\left(\mathrm{CD} 11 \mathrm{~b}^{+} \mathrm{Gr} 1^{+}\right.$ cells) (Figure 1F).

\section{Cyba $\%$ mice show an enrichment of hematopoietic stem progenitor cells in the BM}

In the $\mathrm{BM}$, no differences in cellularity or the percentage of Lin- progenitor cells were observed between knockout (ES Cyba or CR Cyba $a^{-1-}$ ) and wild-type mice (data not shown). Within the Lin cell population we observed an enrichment in HSC (multipotent long-term HSC [LT-HSC] and short-term HSC [ST-HSC]) in both CR Cyba (Figure $2 \mathrm{~A}-\mathrm{B}$ ) and $\mathrm{ES} \mathrm{Cyba}$ - mice (Figure 2C). This increase was around two-fold for both LT- and ST-HSC. No significant differences were found in more-committed myeloid progenitor cells (megakaryocyte-erythrocyte progenitor [MEP], granulocyte-monocyte progenitor [GMP] and common myeloid progenitor [CMP] cells) (Figure 2A-C).

In order to test whether the enrichment of HSC in Cyba mice is cell-autonomous or determined by the niche, BM cells from ES Cyba and wild-type mice were transplanted into lethally irradiated wild-type mice. There was an enrichment of hematopoietic stem progenitor cells (HSPC) populations in animals transplanted with ES Cyba-1-BM cells (LT-HSC, ST-HSC, lymphoid-primed multipotent progenitor [LMPP], MEP and common lymphoid progenitor [CLP] cells) (Figure 2D). These results strongly suggest that the higher proportion of HSC in the Cyba mice does not depend on the influence of the niche, instead it is a cell-autonomous phenomenon.

\section{Cyba $\%$ HSC show an increased proliferation capacity in vivo}

In vivo BrdU incorporation experiments were performed
A

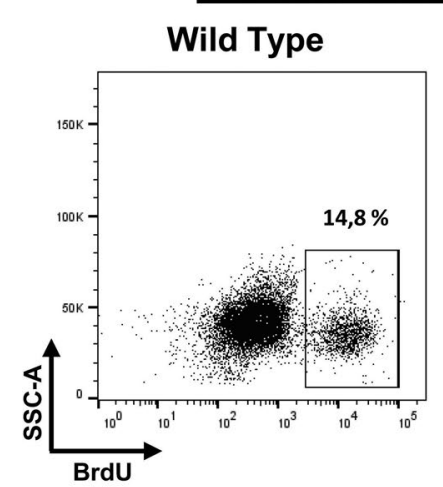

$\mathrm{Lin}^{-} \mathrm{Sca}-1^{+}{ }^{-}-\mathrm{Kit}^{+}(\mathrm{LSK})$

CR Cyba-/-

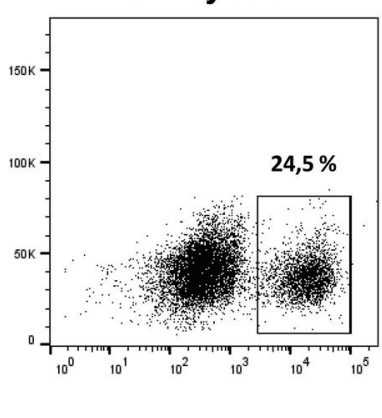

B

- Wild Type - CR Cyba -/-

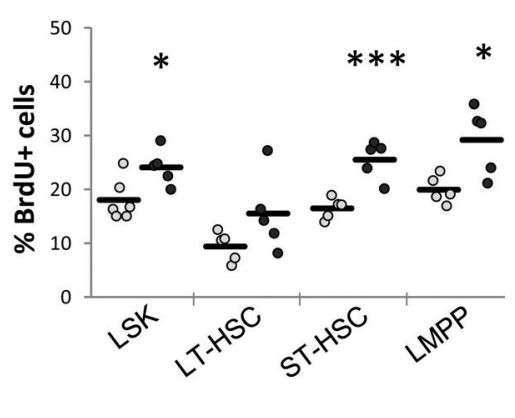

Figure 3. Bone marrow progenitor cells from Cyba mice proliferate more than control cells. CR Cyba and control mice were injected intraperitoneally (IP) with 100 $\mathrm{mg} / \mathrm{kg}$ 5-bromo-2'-deoxyuridine (BrdU), and sacrificed 14 hours later. BrdU incorporation in the hematopoietic stem cells (HSC) bone marrow (BM) populations was analyzed by flow cytometry. (A) A representative experiment of the BrdU incorporation in hematopoietic stem cells (LSK cells) cells is shown. (B) Percentage of BrdU ${ }^{+}$ cells in the different HSC populations. LMPP: lymphoid-primed multipotent progenitors; LT-HSC: long-term HSC; ST-HSC: short-term HSC.

A

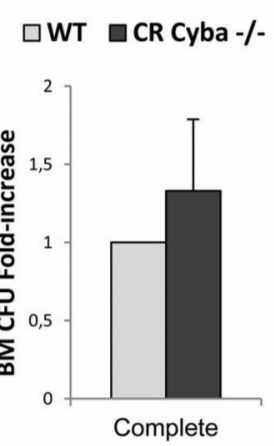

口WT $\square$ CR Cyba - /

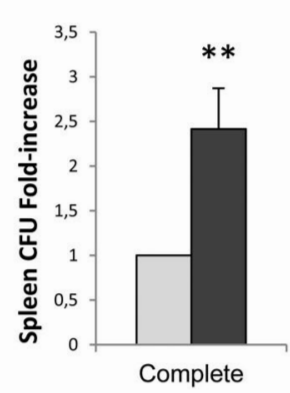

B

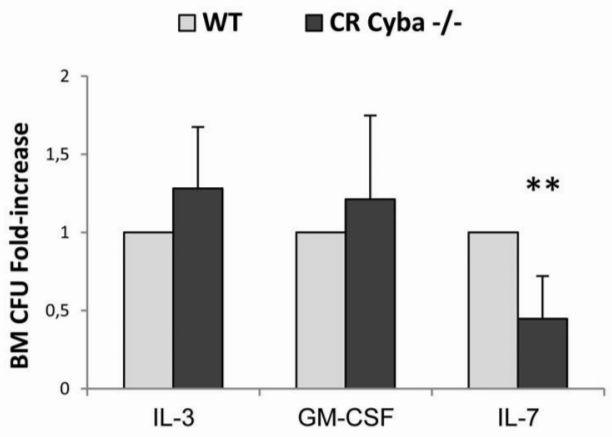

Figure 4. Colony forming assays with bone marrow and spleen cells from Cyba $\%$ mice. The colony forming unit (CFU) ability of bone marrow (BM) and spleen cells in response to complete medium or individual cytokines was tested. (A) CFU ability of BM and spleen cells in response to complete medium ( $\mathrm{n}=6$ and $n=9$, respectively). (B) BM CFU in the presence of IL-3, GM-CSF or IL-7 ( $n=6)$. The mean \pm standard deviation (SD) of the number of colonies normalized with respect to the control is shown. 
to analyze the proliferation capacity of HSPC from CR $C y b a^{-1}$ and control mice. Our results showed a significant increase in $\mathrm{BrdU}$ incorporation in $\mathrm{Lin}^{-} \mathrm{Sca}-1^{+} \mathrm{c}-\mathrm{Kit}^{+}$ hematopoietic stem cells (LSK cells), mainly in ST-HSC and LMPP, but also a general increase in LT-HSC (Figure 3). This higher proliferation potential would explain the enrichment of HSC in Cyba mice.

Cyba $\%$ cells show a lower clonogenic capacity in response to IL-7

We next analyzed the self-renewal potential of BM and spleen cells in response to different cytokines by CFU assays. In the presence of complete media (SCF, IL-3, GMCSF and EPO) BM CR Cyba cells produced a slightly higher number of colonies, though not statistically significant, while spleen CR Cyba cells produced a significantly higher number (Figure 4A). BM cells from CR Cyba mice showed a general trend towards a higher clonogenic capacity in the presence of cytokines that induce myeloid differentiation (IL-3 and GM-CSF), while there was a significant decrease in the number of colonies in the presence of IL-7, a cytokine that drives B-cell differentiation in mice $e^{19}$ (Figure 4B). These results are consistent with the myeloid bias observed in vivo.

Nox1, Cybb and Cyba deficient cells show an increased hematopoietic reconstitution capacity

The results so far support the relevance of NADPH oxidase activity for hematopoiesis. Therefore, an interesting angle would be to delineate the importance of the different NADPH oxidase enzymes. Thus, through competitive transplantation experiments we analyzed the
A
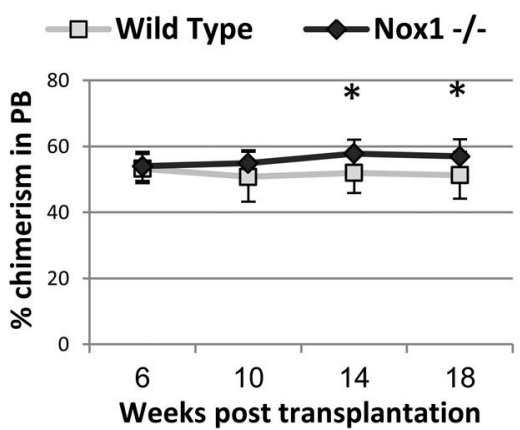

C

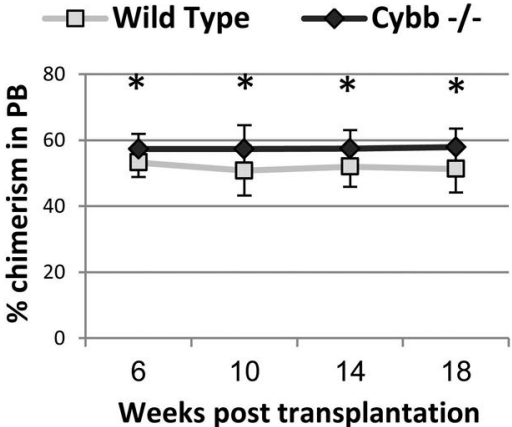

E $\rightarrow-$ Wild Type $\rightarrow$ Nox4 -/

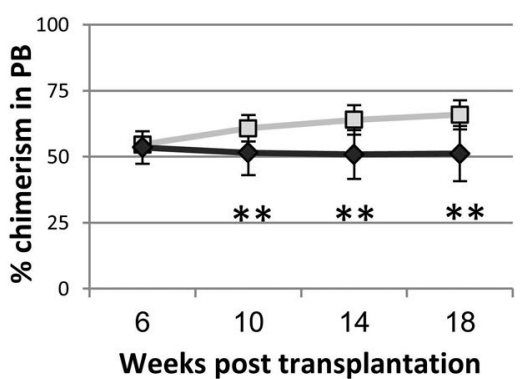

B

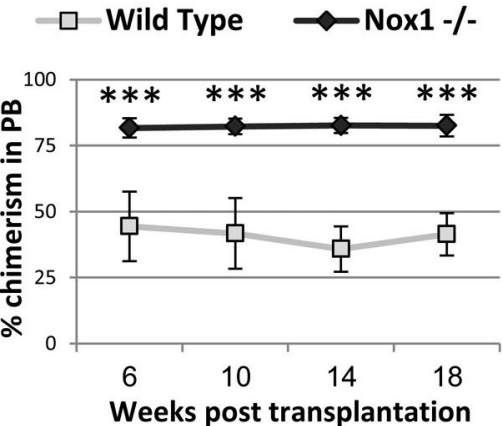

D

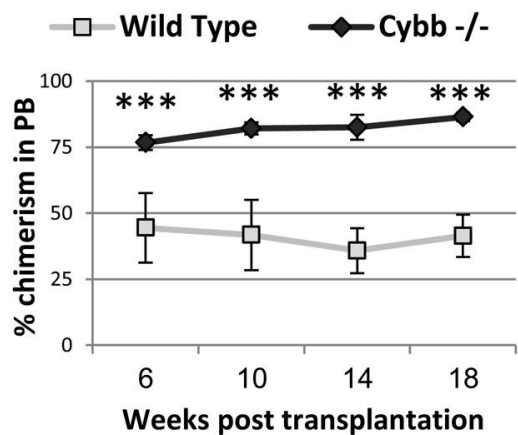

$\mathbf{F}$ $\rightarrow-$ Wild Type $\rightarrow$ Nox4 -/-

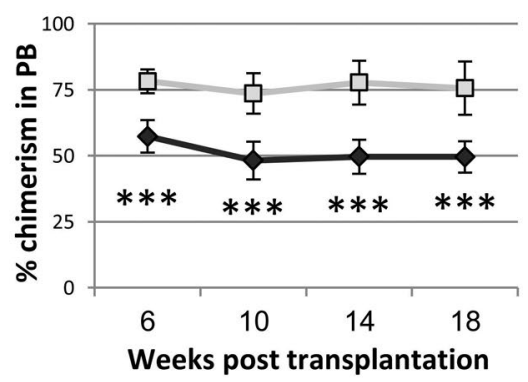

Figure 5. The deficiency of NOX1 and NOX2 increases hematopoietic reconstitution capacity in competitive transplant experiments. The percentage of chimerism throughout time in periperal blood (PB) for the different primary and secondary transplants is shown: (A) Primary and (B) secondary transplants for Nox 1 and control mice $(n=11$ and $n=6$, respectively). (C) Primary and (D) secondary transplants for Cybb and control mice ( $n=11$ and $n=6$, respectively). (E) Primary and (F) secondary transplants for Nox 4 and control mice $(n=10$ and $n=6$, respectively). Graphics show mean \pm standard deviation (SD). 
hematopoietic reconstitution ability of cells lacking NOX1 $\left(\right.$ Nox $\left.1^{-1}\right)$, NOX2 $\left(C y b b^{--}\right)$and NOX4 (Nox4 $\left.4^{-1}\right)$. BM cells from these mice strains were challenged with the same amount of BM cells from wild-type mice, and were transplanted into lethally irradiated recipient wild-type mice (Figure 5).

The lack of NOX1 (Nox1 $\left.1^{-1}\right)$ and $\operatorname{NOX} 2\left(C_{y b} b^{-1}\right)$ conferred a mild but significant increase in reconstitution compared to wild-type cells in primary recipients (Figure $5 \mathrm{~A}, \mathrm{C})$. Interestingly, Nox $4^{-/}$cells showed the opposite, with a slightly lower reconstitution capacity in primary transplants (Figure 5E). In order to test this issue further, secondary transplants were performed in the three settings. While Nox $1^{-}$and $C y b b^{-}$once again showed a higher reconstitution capacity than wild-type cells (Figure 5B, D), Nox 4 cells displayed the same percentage of chimerism $(50 \%)$ as in the primary transplant (Figure 5F). These results validate those obtained in the primary transplants and suggest a differential role for each Nox isoform during in vivo hematopoiesis.

In agreement with the results described for Nox ${ }^{-1}$ and $C y b b^{-1}$, competitive transplant experiments performed with ES Cyba mice and wild-type littermates offered a very subtle enhancement of reconstitution of $\mathrm{Cyba}$ cells (Figure 6A-B), which could also be observed in secondary transplants (Online Supplementary Figures 4A-B).

When we analyzed the lineages within the ES Cybatransplanted cells, there was a significant increase in

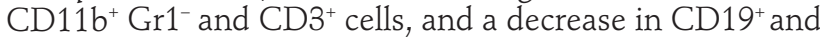
$\mathrm{B}_{22} 0^{+}$cells (Figure 6C). These features were also evidenced in secondary transplants (Online Supplementary Figure $54 \mathrm{C}$ ). Moreover, there was also an enrichment of LT-HSC and lineage-committed progenitors (LK) and a general increase in LMPP and LSK in the ES Cyba transplanted cells (Figure 6D). These features are much like those found in the ES Cyba mice (Figure 1E and Figure $2 \mathrm{C})$, strongly suggesting once again that the hematopoietic alteration we have found in $C y b a^{-1}$ mice is the result of cell-endogenous causes and not due to the influence of the niche.

Unlike Cyba cells, in the transplant experiments performed with $\mathrm{Nox}^{-1}$ and $\mathrm{Cyb} \mathrm{b}^{--}$deficient cells, no clear differences were found in regard to the different hematopoietic lineages (Online Supplementary Figure S5A). No signifi-
A

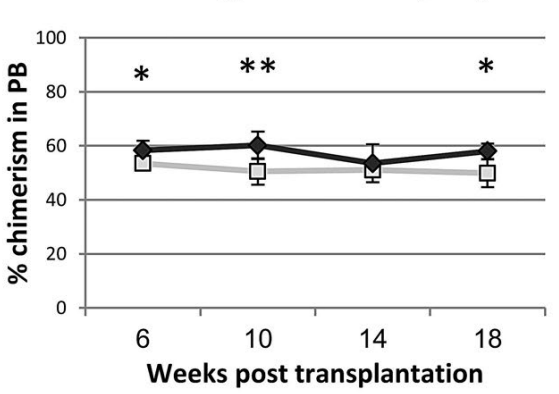

B

\section{○ Wild Type • ES Cyba -/-}

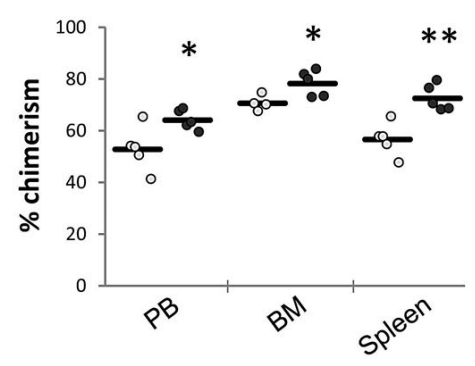

C

○ Wild Type • ES Cyba -/-
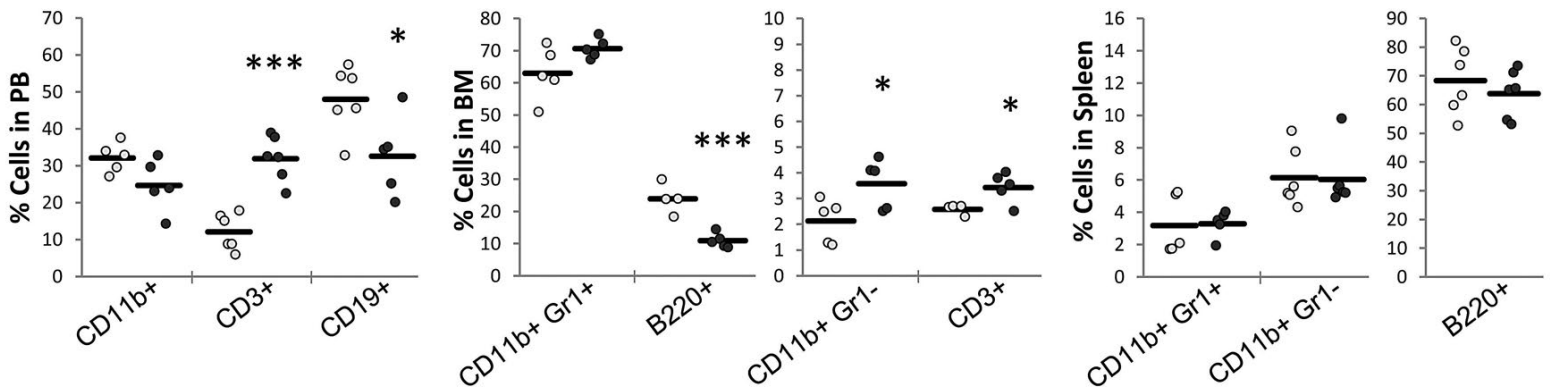

D

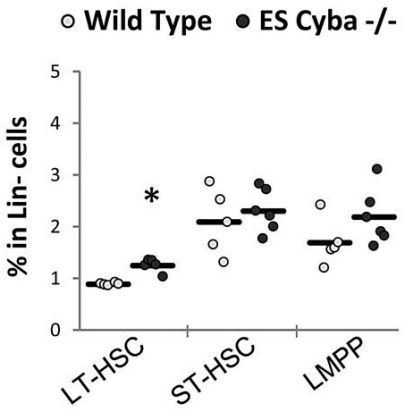

Figure 6. The deficiency of $\mathrm{p} 22^{\text {phox }}$ induces a slight increase in hematopoietic reconstitution capacity in competitive transplant experiments. Lethally irradiated wild-type recipient mice were subjected to competitive hematopoietic transplant experiments with ES Cyba $\%$. Wild-type littermates were used as control. (A) Percentage of chimerism throughout time in peripheral blood (PB) in primary transplant. Graphic show mean \pm SD $(n=6)$. (B) Percentage of chimerism in PB, bone marrow (BM) and spleen 20 weeks posttransplantation. (C) Hematopoietic mature lineages in PB, BM and spleen of the transplan-ted animals coming from $\mathrm{Cyba} \%$ and control cells. (D) Hematopoietic progenitor stem cells (HSPC) in BM of the transplanted animals coming from Cyba $\%$ and control cells. LMPP: lymphoid-primed multipotent progenitors; LT-HSC: long-term HSC; STHSC: short-term HSC. 
A

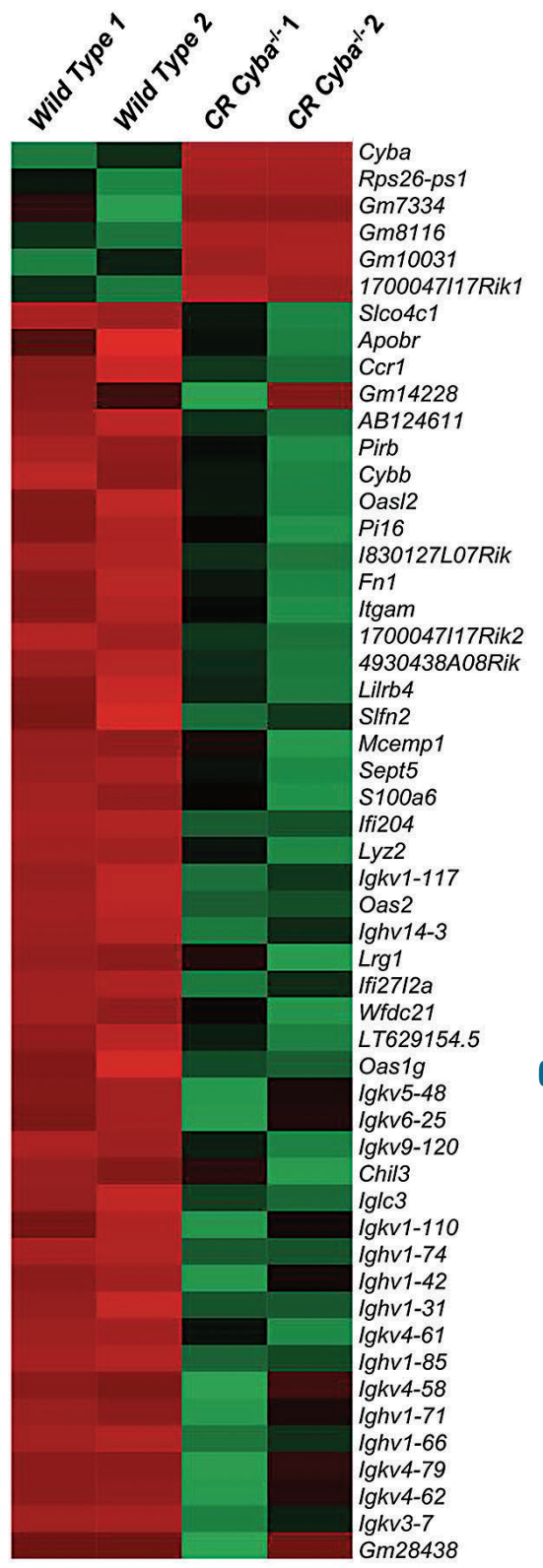

Z-Score

$\begin{array}{lll}-1.2 & 0.2 & 1.5\end{array}$
B

Processes related to $I g$ and $L y z 2$ genes:

1- Phagocytosis, recognition

3- Positive regulation of $\mathrm{B}$ cell activation Processes related to Oas/2, Oas1g, Oas2,

5- Phagocytosis, engulfment

6- Complement activation, classical pathway

Ifi27/2a, Ifi204 and SIfn2 genes:

Iffi27I2a, Ifi204 and

2- Regulation of ribonuclease activity

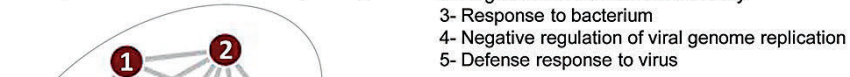

-

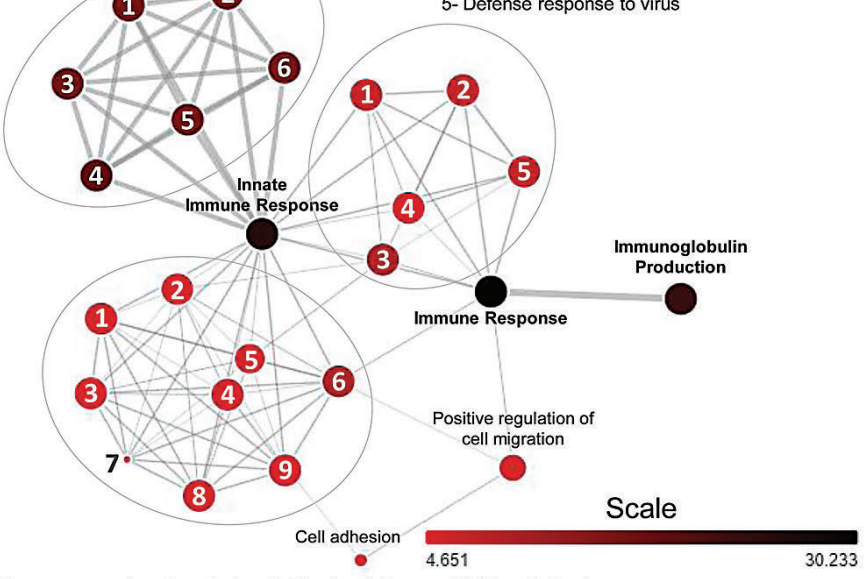

Processes related to Cyba, Cybb, Lrg1, Itgam, Chil3 and Ccr1 genes:

- Superoxide anion generation

2- Positive regulation of endothelial cell proliferation

3- Respiratory burst

4- Positive regulation of superoxide anion generation

5- Positive regulation of angiogenesis

6- Inflammatory response

7- Oxidation-reduction process

8- Hydrogen peroxide biosynthetic process

9-Superoxide metabolic process

C

Pathways related to $F \boldsymbol{n} 1$ and Itgam genes:

1-Amoebiasis

2- - Cell surface interactions at the vascular wall

4- Focal adhesion

5- Extracellular matrix organization

6- Regulation of actin cytoskaton

7- Focal adhesion-PI3K-Akt-mTOR-signalling pathway

8- Integrin cell surface interactions

Pathways related to Oas1g and Oas2 genes: Measles
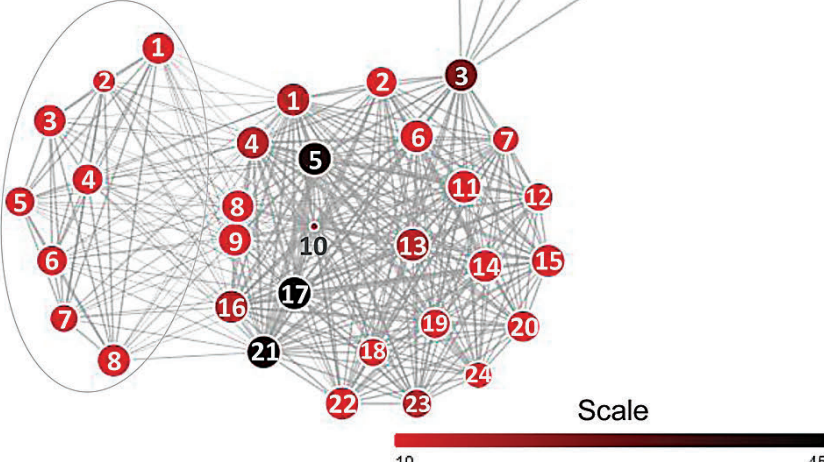

12- VEGFA-VEGFR2 pathway

13- Osteoclast differentiation (Pirb)

14- Antigen processing-Cross presentation

15- RHO GTPases activate NADPH oxidases

16- Leukocyte transendothelial migration (Itgam)

17- Immune System (Itgam, Lyz2, Pirb, Mcemp1, Lrg1, Iglc3, Slco4c1) 18- Signaling by VEGF

9- RHO GTPase effectors

- Fluid shear stress and atherosclerosi

21- Neutrophil degranulation (Itgam, Lyz2, Pirb, Mcemp1, Lrg1, Slco4c1) 22- Cross-presentation of particulate exogenous antigens (phagosomes) 23- Adaptative Immune System (Iglc3) 24- Cellular responses to stress

Figure 7. Transcriptome analysis of Lin cells from Cyba and control mice. Lin cells were immunopurified from the bone marrow (BM) of two CR Cyba and two control mice. The gene expression profile was analyzed by RNA sequencing. (A) Heat-map showing Z-scores of the expression values (normalized as transcript per million [TPM] values) of genes with significantly altered expression in Cyba cells. (B) Network of functional analysis results for processes. Each node represents a functional category. The percentage of significant differentially-expressed genes annotated by the different categories on the GO database is represented by colors, as shown by the scale in the figure. Connecting lines show the relationships between different functional categories; the width of the lines is proportional to the genes in common. (C) Network of functional analysis results for pathways. 
A

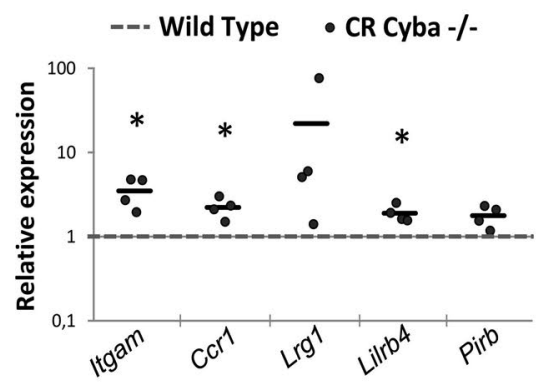

C

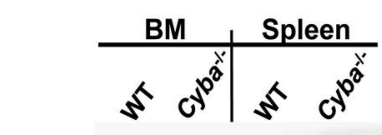

$72 \mathrm{kDa}$ -

$55 \mathrm{kDa}$ -

$36 \mathrm{kDa}$ -

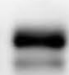

$36 \mathrm{kDa}$ -

IGs

$28 \mathrm{kDa}$ -

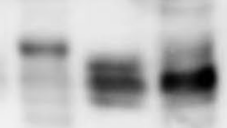

B

--- Wild Type - CR Cyba -/-

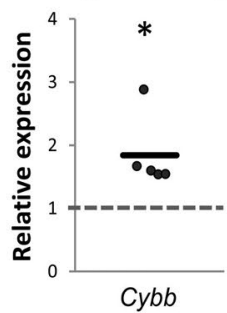

- Wild Type • CR Cyba -/-
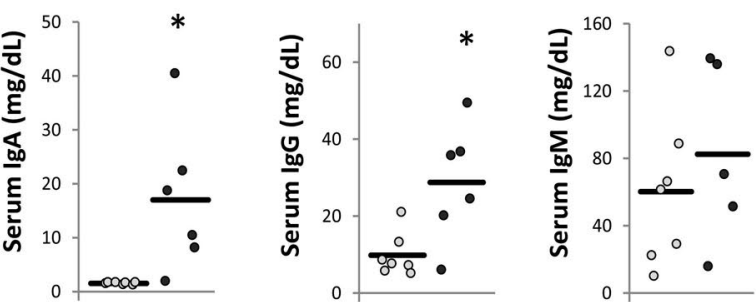

$130 \mathrm{kDa}$ -

VINCULIN

E

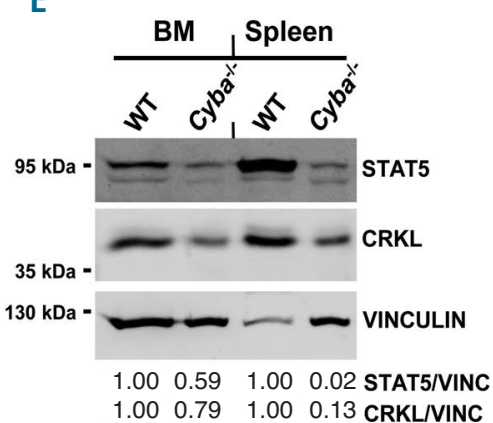

F

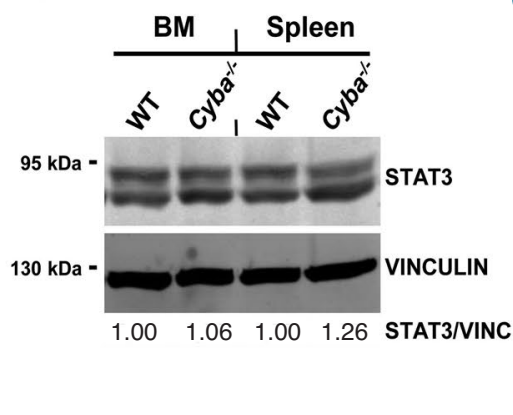

G --- Wild Type - CR Cyba -/-

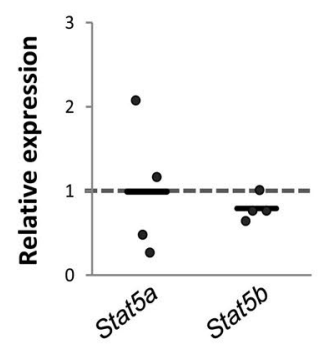

H

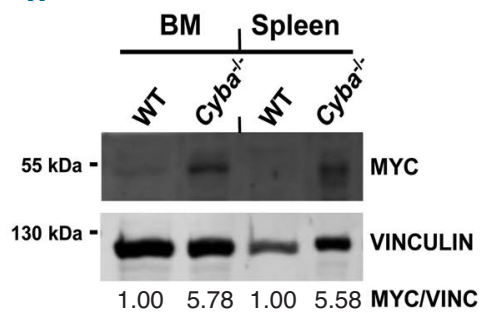

Figure 8. p22 phox deficiency increases myeloid gene expression, immunoglobulin serum levels and induces the downregulation of STAT5 protein. (A) The expression of several myeloid genes that were upregulated according to RNA sequencing data was analyzed by quantitave RT-PCR (qRT-PCR) in Lin cells. Results show the relative expression of these genes in CR Cyba mice with respect to control mice. The discontinuous line represents expression in control mice. (B) Relative expression of Cybb in Lin cells from CR Cyba mice with respect to control mice analyzed by qRT-PCR. (C) Immunoglobulin protein levels in the bone marrow (BM) and spleen of CR Cyba and control mice ( $n=4)$. (D) Immunoglobulin serum levels in CR Cyba and control mice. Levels of IgA, IgG and IgM in serum were analyzed by ELISA. Results are shown as $\mathrm{mg} / \mathrm{dL}$. The steady state level in BM and spleen of the following proteins was analyzed: (E) STAT5 and CRKL ( $n=4)$, (F) STAT3 ( $n=3$ ). (G) Stat5a and Stat5b expression was analyzed by qRT-PCR in Lin cells. Results show the relative expression of these genes in CR Cyba mice with respect to control mice. (H) MYC protein levels in BM and spleen from CR Cyba and control mice $(n=3)$. 
cant differences were found regarding HSPC, though $C y b b^{-1}$ cells showed a general increase in the LT-HSC and ST-HSC populations (Online Supplementary Figure S5B).

Interestingly, lineage analysis of Nox $4^{-1}$ cells offered some similarities to the differences described in the transplants performed with ES Cyba mice, such as, for example, a significant increase in $\mathrm{CD}_{11 \mathrm{~b}^{+}} \mathrm{Gr}^{-}$myeloid cells in $\mathrm{BM}$, and the same changes in $\mathrm{CD}^{+}$and $\mathrm{CD}^{+} 9^{+}$cells (Online Supplementary Figure S5C).

\section{Cyba deficiency increases the expression of immunoglobulin genes}

In order to gain some insight regarding the previous results we performed transcriptome profile analyses in Lin $^{-}$cells from control and CR Cyba mice by RNA sequencing. We found 47 upregulated and five downregulated genes in Cyba cells (Figure 7A). In line with the myeloid bias described above, among the upregulated genes there were several genes encoding proteins highly expressed in myeloid cells, such as Itgam (CD11b), Pirb (CD85A), Lilrb4 (CD85K), Ccr1(CD191) and Lrg1. Intriguingly, there was also an upregulation of $C y b b$ mRNA expression in the Cyba- cells. These results were corroborated by quantitative RT-PCR (qRT-PCR) (Figure 8A-B).

However, the most striking result was the upregulation of 18 immunoglobulin genes of both heavy variable (Ighv) and $\kappa$ light variable (Igkv) chains. In line with this, we detected an increased expression of immunoglobulins in the BM and spleen of CR Cyba mice (Figure 8C), suggesting an increased production of immunoglobulins by $\mathrm{CR}$ Cyba mice. Confirming this hypothesis, CR Cyba mice showed a significant increase in IgA, in IgG, in serum, and a general increase in IgM that did not reach statistical significance (Figure 8D). All in all, these results are in agreement with an exacerbated production of immunoglobulins by CR Cyba ${ }^{-1}$ mice.

Functional analyses of these results (Figure 7B) suggested that the innate immune response and immunoglobulin production processes are severely affected by the lack of Cyba, with a high proportion of genes involved in these processes among the miss-regulated genes in $\mathrm{Cyba}$ - mice. Accordingly, the response to bacteria and defense against viruses were among the altered processes. Moreover, as expected, processes related to superoxide anion generation are also hampered. Of note, other fundamental processes such cell migration and cell adhesion also seem to be affected by the lack of Cyba (Figure 7B). In the same line, pathway analyses also suggest the alteration of the innate immune response, and pathways related with cell adhesion and migration (Figure 7C). Signaling pathways such as VEGF, Rho GTPases and PI3K-AKT-mTOR appear among the potentially altered pathways (Figure 7C). In support of this, we observed that activation of AKT1 in response to several hematopoietic cytokines was somewhat impaired in Cyba cells (Online Supplementary Figure S6A).

\section{Cyba deficiency leads to the downregulation of STAT5}

Given the possible implication of NADPH oxidases in the regulation of the signaling pathways governing hematopoiesis ${ }^{2,3}$ we analyzed the activation of several signaling pathways by immunoblotting. No differences were found in the activation of ERK or in levels of $\beta$-CATENIN (Online Supplementary Figures 6B-C). However, our analy- ses revealed a sharp decrease in STAT5 protein in BM and spleen $\mathrm{Cyba}^{-1}$ cells (Figure 8E and Online Supplementary Figure 6D). In contrast, no differences were found regarding the expression of STAT3 protein (Figure 8F), which highlights the specificity of the decrease in STAT5 in Cybar- mice. No differences in Stat5a and Stat $5 b$ mRNA between $\mathrm{Cyba}^{-/}$and control mice were detected in the RNA-seq analyses (Figure 7), which was corroborated by qRT-PCR (Figure 8G). Therefore, this strongly suggests that the decrease in STAT5 in Cyba mice occurs at the protein level. Moreover, the levels of CRKL, a protein that can form functional heterodimers with STAT $5,{ }^{20}$ were also downregulated in Cyba ${ }^{-/}$mice (Figure 8E). Finally, the levels of MYC, another transcription factor important for hematopoiesis, ${ }^{21}$ were also upregulated in $\mathrm{Cyba}^{-1}$ mice (Figure 8H).

\section{Discussion}

There is accumulating evidence supporting the importance of ROS and redox signaling in hematopoietic differentiation. ${ }^{3} \mathrm{NADPH}$ oxidases would be ideal candidates as an adjustable source of ROS during hematopoiesis, given that they can be activated by extracellular signals, including hematopoietic cytokines. ${ }^{22-25}$ Our previous results support this working hypothesis, since we have shown the relevance of ROS production by NADPH oxidases for regulating in vitro megakaryocytic differentiation. ${ }^{12}$

Therefore, we questioned whether NADPH oxidase activity would be required for in vivo hematopoiesis. The difficulty of this study lies in the fact that many cells express several NADPH oxidases simultaneously. Mouse hematopoietic progenitors express three different $\mathrm{p} 22^{\text {phox }}$ dependent NOX (NOX1, NOX2 and NOX4), therefore, we started by generating $\mathrm{Cyba}$ - mice.

Flow cytometry analyses supported the existence of a myeloid bias in ES Cyba mice, which could also be observed in the CR model, though at a weaker level. Nevertheless, we found the upregulation of myeloid genes in Lin cells from CR Cybar mice, also supporting the existence of a myeloid bias in the CR Cyba mice. Although the genetic background of the ES and CR models (C57BL/6N and C57BL/6J respectively) are very closely related, ${ }^{26}$ we cannot rule out that this might account for the differences regarding the myeloid bias. Moreover, the weaker phenotype in the CR Cyba mice could be in line with phenomena associated with the CRISPR/Cas9 tool, such as the activation of genetic compensation mechanisms, ${ }^{27}$ and the residual expression of the targeted protein. ${ }^{28}$

A remarkable increase in HSC populations is observed in Cyba mice, which correlates with a higher cellular proliferation capacity, as shown by the in vivo BrdU incorporation assays. It has been suggested before that MYC upregulation can lead to the expansion of HSPC, ${ }^{21}$ so the increased expression of MYC in BM Cyba mice could explain this effect in our cells. Thrombopoietin (TPO) has recently been identified as a crucial cytokine for the control of HSC quiescence. ${ }^{29}$ TPO signaling depends on the activation of STAT5. ${ }^{30}$ In turn, the importance of STAT5 for maintaining HSC quiescence has also been reported. ${ }^{31}$ Considering the dramatic decrease in STAT5 protein levels in Cyba mice, hampered TPO signaling as a consequence of diminished STAT5 activation could shift the balance 
from quiescence towards an increase in cell proliferation. In line with this hypothesis NOX2 and NOX4 ROS production seems to be required for maintaining the stemness of induced pluripotent stem cells. ${ }^{32}$

We have addressed the relevance of NOX isoforms for hematopoiesis through competitive transplantation exper-

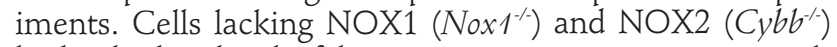
had a higher level of hematopoietic reconstitution with respect to wild-type cells. The hematopoietic reconstitution ability of $C y b b^{-1}$ cells has been reported through competitive transplant experiments, showing an enhanced hematopoietic reconstitution of adult BM Cybb-r cells at the beginning of the experiment, which is lost at later time points. ${ }^{33}$ Our results would be similar to those reported by Weisser et al. ${ }^{33}$ since at short time points we also found a slight reconstitution advantage in $\mathrm{Cy}_{\mathrm{b}} \mathrm{b}^{-/}$cells, though in our case said advantage is kept throughout time in the primary transplant. Moreover, we performed secondary transplants that confirmed the greater reconstitution ability of not only $C y b b^{-1}$ cells, but also of Nox $1^{-}$and $C y b a^{-1}$ cells. These results support those obtained by us in primary transplants. While Weisser et al. ${ }^{33}$ used a limited number of purified HSC that were modified by lentivirus infection before the transplant, we used $3 \times 10^{6}$ whole BM cells for the transplant. We wonder whether the different progenitor cell numbers or the presence of more mature progenitors in our assays could be responsible for the sustained advantage of reconstitution observed. Another interesting area may be the upregulation of IL-1 $\beta$ signaling caused by the hyperinflammation linked to the CGD. According to the data presented by Weisser et al. ${ }^{33} \mathrm{IL}-1 \beta$ signaling can lead to the impaired reconstitution capacity of the HSC. The group comments in their methods section that animals with overt infections were not included in their study, which suggests they may have used animals with some kind of inflammatory pathology. In our case, none of the animals used showed any sign of inflammation or disease, so it is likely that a different level of IL-1 signaling could explain the differences in our results. While preparing our manuscript, another article was published reporting a lower reconstitution ability for $C y b b^{-1}$ cells in primary transplants. ${ }^{34}$ Adane et al. ${ }^{34}$ also used whole BM for their assays, but again a more limited cell number was used, and unlike us, their findings were not confirmed by secondary transplants.

Together these results show a certain variability in the outcome of these assays, which is also supported by the fact that Weisser et al. ${ }^{33}$ did not find any difference in the transplants when using $C y b b^{-1}$ fetal liver cells. ${ }^{33}$

Despite these differences, Weisser et al. ${ }^{33}$ report that $C y b b^{--}$mice show an increased number of HPC, with a higher proliferation rate. They also show an increase in the formation of myeloid CFU by $C y b b^{-1} \mathrm{BM}$ cells. All these results are in line with our findings for $C y b a^{-/}$mice, and combined would support the importance of NOX2 and $\mathrm{p} 22^{\text {phox }}$ for the control of HSPC function.

Nox $4^{-1-}$ transplanted cells showed certain lineage alterations, similar to those observed in the Cybar mice. All this considered, we hypothesize that NOX1 and NOX2 could be involved in the regulation of HSC homeostasis, while NOX4 might be important for lineage decisions given its implication in cell differentiation. ${ }^{2}$

The lack of phagocyte oxidase activity in $\mathrm{Cyba}^{-/}$mice would lead to a defective immune response, as suggested by analysis of our RNA-seq results. Moreover, alterations of the NOD-like receptor signaling pathway, involved in the recognition of pathogen derived patterns, ${ }^{35}$ or the alteration of antigen processing and presentation pathways ${ }^{36}$ suggests that adaptive immunity could also be compromised in Cyba mice. Additionally, we detected an exacerbated production of immunoglobulins in $C y b a^{-/}$mice, in agreement with the high level of IgG in CGD human subjects. ${ }^{37}$ An interesting question is the molecular mechanism leading to this scenario. IL-7 signaling drives B cell lymphopoiesis in mice. ${ }^{38}$ STAT5 and the PI3K/AKT pathway are the downstream effectors of IL-7 during B cell development. ${ }^{39}$ The lack of Stat $5 a$ and Stat 56 blocks B cell development. ${ }^{19}$ STAT5 is not only required for maintaining cell survival during B-cell differentiation, ${ }^{40}$ but also for regulating Ig rearrangement, ${ }^{41}$ so much so that IL-7 signaling prevents premature Igk rearrangement through STAT5 activation. ${ }^{19}$ Moreover, there are studies suggesting that STAT5b deficiency in humans leads to an increased production of immunoglobulin $\mathrm{E}^{42}$ and $\mathrm{G}^{43}$. Therefore, we hypothesize that STAT5 downregulation and the reduced response to IL-7 must be key factors for the upregulation of immunoglobulins observed in $C y b a^{-1-}$ mice.

Analyses of STAT5 protein stability in the literature are rather scarce; STAT5 can be degraded by calpain ${ }^{44}$ and caspase $-3 .{ }^{45}$ Moreover, it has also been shown that the redox sensitive phosphatase DUSP4 can trigger STAT5 protein degradation through proteasome and lysosome pathways. ${ }^{46}$ In line with that, it could be hypothesized that a lower level of ROS in Cyba mice may allow a higher level of DUSP4 activity, thus leading to STAT5 protein degradation.

In summary, by downregulating NADPH oxidase activity in hematopoietic cells through the deletion of the Cyba gene, we show the relevance of such activity for in vivo hematopoiesis. The lack of Cyba induces a myeloid bias and promotes the enrichment of HSC populations, together with an increased proliferation potential. Moreover, the lack of $\mathrm{p} 22^{\text {phox }}$ hinders the activation of the PI3K-AKT pathway, and induces STAT5 downregulation. This would jeopardize the activation of IL-7 signaling, which would explain the increased immunoglobulin production in Cybar mice.

\section{Disclosures \\ No conflicts of interest to disclose}

\section{Contributions}

$R P B$ performed experiments, analyzed data, assembled figures, revised the manuscript. MRG and APF performed experiments and revised the manuscript. IGT and MSM generated the Cyba-/- mice. AHH conceived and designed experiments, performed experiments, analyzed data and wrote the manuscript.

\section{Acknowledgments}

We thank L. Stockdale for reviewing the English version of this manuscript.

\section{Funding}

This work was funded by the Spanish Ministry of Economy and Competitiveness (MINECO) (BFU2014-56490-R) and Ramón Areces Foundation (CIV17A2822). RPB, MRG and $A P F$, were recipients of pre-doctoral fellowships from the Regional Government of Castilla and Leon, Spain and ERDF funds. 


\section{References}

1. Prieto-Bermejo R, Hernández-Hernández Á. The importance of $\mathrm{NADPH}$ oxidases and redox signaling in angiogenesis. Antioxidants (Basel). 2017;6(2):32.

2. Sardina JL, Lopez-Ruano G, SanchezSanchez B, Llanillo M, HernándezHernández Á. Reactive oxygen species: are they important for haematopoiesis? Crit Rev Oncol Hematol. 2012;81(3):257-274

3. Prieto-Bermejo R, Romo-González M, PérezFernández A, Ijurko C, HernándezHernández Á. Reactive oxygen species in haematopoiesis: leukaemic cells take a walk on the wild side. J Exp Clin Cancer Res. 2018;37(1):1-18.

4. Bedard K, Krause K-H. The NOX family of ROS-generating NADPH oxidases: physiology and pathophysiology. Physiol Rev. 2007:87(1):245-313.

5. Nauseef WM. Biological roles for the NOX family NADPH oxidases. J Biol Chem. 2008:283(25):16961-16965.

6. Battersby AC, Cale AM, Goldblatt D, Gennery AR. Clinical manifestations of disease in X-linked carriers of chronic granulomatous disease. J Clin Immunol. 2013; 33(1573-2592):1276-1284.

7. Suh Y-A, Arnold RS, Lassegue B, et al. Cell transformation by the superoxide-generating oxidase Mox1. Nature. 1999;401 (6748):7982.

8. Rinnerthaler $\mathrm{M}$, Buttner $\mathrm{S}$, Laun $\mathrm{P}$, et al. Yno1p/Aim14p, a NADPH-oxidase ortholog, controls extramitochondrial reactive oxygen species generation, apoptosis, and actin cable formation in yeast. Proc Natl Acad Sci. 2012;109(22):8658-8663.

9. Kubli DA, Sussman MA. Eat, breathe, ROS: controlling stem cell fate through metabolism. Expert Rev Cardiovasc Ther. 2017; 15(1477-9072):345-356.

10. Maryanovich M, Gross A. A ROS rheostat for cell fate regulation. Trends Cell Biol. 2013;23(3):129-134

11. Jung H, Choi I. Thioredoxin-interacting protein, hematopoietic stem cells, and hematopoiesis. Curr Opin Hematol. 2014; 21(4):265-270.

12. Sardina IL, López-Ruano G, Sánchez-Abarca LI, et al. p22 $2^{\text {phox }}$-dependent $\mathrm{NADPH}$ oxidase activity is required for megakaryocytic differentiation. Cell Death Differ. 2010;17(12):1842-1854

13. Sanchez-Sanchez B, Gutierrez-Herrero S, Lopez-Ruano G, et al. NADPH oxidases as therapeutic targets in chronic myeloid leukemia. Clin Cancer Res. 2014; 20(15):4014-4025

14. Yamazaki T, Kawai C, Yamauchi A, Kuribayashi F. A highly sensitive chemiluminescence assay for superoxide detection and chronic granulomatous disease diagnosis. Trop Med Health. 2011;39(2):41-45.

15. López-Ruano G, Prieto-Bermejo R, Ramos TL, et al. PTPN13 and $\beta$-catenin regulate the quiescence of hematopoietic stem cells and their interaction with the bone marrow niche. Stem Cell Rep. 2015;5(4):516-531.

16. Sardina JL, López-Ruano G, Prieto-Bermejo
$\mathrm{R}$, et al. PTPN13 regulates cellular signalling and $\beta$-catenin function during megakaryocytic differentiation. Biochim Biophys Acta Mol Cell Res. 2014;1843(12):2886-2899.

17. Nakano Y, Longo-Guess CM, Bergstrom DE, Nauseef WM, Jones SM, Bánfi B. Mutation of the Cyba gene encoding $\mathrm{p} 22^{\text {phox }}$ causes vestibular and immune defects in mice. J Clin Invest. 2008;118(3):1176-1185

18. Paffenholz R, Bergstrom RA, Passutto F, et al. Vestibular defects in head-tilt mice result from mutations in Nox3, encoding an NADPH oxidase. Genes Dev. 2004; 18(5):486-491.

19. Clark MR, Mandal M, Ochiai K, Singh H Orchestrating B cell lymphopoiesis through interplay of IL-7 receptor and pre-B cell receptor signalling. Nat Rev Immunol. 2014; 14(2):69-80

20. Brierley MM, Fish EN. Stats: multifaceted regulators of transcription. J Interf Cytokine Res. 2006;25(12):733-744.

21. Wilson A, Murphy MJ, Oskarsson T, et al. cMyc controls the balance between hematopoietic stem cell self-renewal and differentiation. Genes Dev. 2004; 18(22): 2747 2763

22. Huang H, Kim HJ, Chang EJ, et al. IL-17 stimulates the proliferation and differentiation of human mesenchymal stem cells: implications for bone remodeling. Cell Death Differ. 2009;16(1476-5403):1332-1343.

23. Sharma P, Chakraborty R, Wang L, et al. Redox regulation of interleukin-4 signaling. Immunity. 2008:29(4):551-564

24. Hurtado-Nedelec M, Csillag-Grange MJ, Boussetta $T$, et al. Increased reactive oxygen species production and $\mathrm{p} 47$ phox phosphorylation in neutrophils from myeloproliferative disorders patients with JAK2 (V617F) mutation. Haematologica. 2013;98(1592 8721):1517-1524

25. Zhu OS, Xia L, Mills GB, Lowell CA, Touw IP, Corey SJ. G-CSF induced reactive oxygen species involves Lyn-PI3-kinase-Akt and contributes to myeloid cell growth. Blood. 2006;107(0006-4971):1847-1856.

26. Pettitt SJ, Liang Q, Rairdan XY, et al. Agout C57BL/6N embryonic stem cells for mouse genetic resources. Nat Methods. 2009; 6(7):493-495

27. Ma Z, Zhu P, Shi H, et al. PTC-bearing mRNA elicits a genetic compensation response via Upf3a and COMPASS components. Nature. 2019;568(7751):259-263.

28. Smits AH, Ziebell F, Joberty G, et al. Biological plasticity rescues target activity in CRISPR knockouts. bioRxiv. 2019;16(11): 1087-1093

29. de Graaf CA, Metcalf D. Thrombopoietin and hematopoietic stem cells. Cell Cycle. 2011:10(10):1582-1589.

30. Drayer AL, Boer A-K, Los EL, Esselink MT, Vellenga E. Stem cell factor synergistically enhances thrombopoietin-induced STAT5 signaling in megakaryocyte progenitors through JAK2 and Src Kinase. Stem Cells 2005:23(2):240-251

31. Schepers H, Wierenga ATJ, Vellenga E Schuringa JJ. STAT5-mediated self-renewal of normal hematopoietic and leukemic stem cells. Jak-Stat 2012;1(1):13-25.
32. Kang X, Wei X, Jiang L, et al. Nox2 and Nox4 regulate self-renewal of murine inducedpluripotent stem cells. IUBMB Life. 2016; 68(12):963-970.

33. Weisser M, Demel UM, Stein S, et al Hyperinflammation in patients with chronic granulomatous disease leads to impairment of hematopoietic stem cell functions. Allergy Clin Immunol. 2016;138(1):219228.e9.

34. Adane B, Ye $\mathrm{H}$, Khan $\mathrm{N}$, et al. The hematopoietic oxidase NOX2 regulates selfrenewal of leukemic stem cells. Cell Rep. 2019;27(1):238-254.e6.

35. Kapetanovic R, Cavaillon JM. Early events in innate immunity in the recognition of microbial pathogens. Expert Opin Biol Ther 2007;7(6):907-918

36. Murat P, Tellam J. Effects of messenger RNA structure and other translational control mechanisms on major histocompatibility complex-I mediated antigen presentation. Wiley Interdiscip Rev RNA. 2015;6(2):157171

37. Wu J, Wang WF, Zhang YD, Chen TX Clinical features and genetic analysis of 48 patients with chronic granulomatous disease in a single center study from Shanghai, China (2005-2015): new Studies and a literature review. J Immunol Res. 2017;2017: 8745254

38. Petkau G, Turner M. Signalling circuits that direct early B-cell development. Biochem J 2019;476(5):769-778.

39. Hamel KM, Mandal M, Karki S, Clark MR Balancing proliferation with IgK recombination during B-lymphopoiesis. Front Immunol. 2014:5:139.

40. Malin S, McManus S, Cobaleda C, et al. Role of STAT5 in controlling cell survival and immunoglobulin gene recombination durin pro-B cell development. Nat Immunol. 2010;11(2):171-179.

41. Heltemes-Harris LM, Farrar MA. The role of STAT5 in lymphocyte development and transformation. Curr Opin Immunol. 2012, 24(2):146-152.

42. Klammt J, Neumann D, Gevers EF, et al Dominant-negative STAT5B mutations cause growth hormone insensitivity with short stature and mild immune dysregulation. Nat Commun. 2018;9(1):2105.

43. Nadeau K, Hwa V, Rosenfeld RG. STAT5b deficiency: an unsuspected cause of growth failure, immunodeficiency, and severe pulmonary disease. J Pediatr. 2011;158(5):701708

44. Oda A, Wakao H, Fujita H. Calpain is a signal transducer and activator of transcription (STAT) 3 and STAT5 protease. Blood. 2002; 99(5):1850-1852

45. Pietschmann K, Bolck HA, Buchwald M, et al Breakdown of the FLT3-ITD/STAT5 axis and synergistic apoptosis induction by the histone deacetylase inhibitor panobinostat and FLT3-specific inhibitors. Mol Cancer Ther 2012;11(11):2373-2383.

46. Hsiao W-Y, Lin Y-C, Liao F-H, Chan Y-C Huang C-Y. Dual-specificity phosphatase 4 regulates STAT5 protein stability and helper T cell polarization. PLoS One. 2015;10(12): e0145880. 